\title{
Pilot study of pulmonary arterial branch sealing using energy devices in an ex vivo model
}

\author{
Moishe Liberman, MD, PhD, Mohamed Khereba, MB, BCh, Eric Goudie, MD, Jordan Kazakov, MD, \\ Vicky Thiffault, RN, Edwin Lafontaine, MD, and Pasquale Ferraro, MD
}

\begin{abstract}
Objective: Vascular endostaplers are bulky and can be dangerous when dividing small pulmonary arterial (PA) branch vessels during video-assisted thoracoscopic lobectomy. We aimed to evaluate and compare the immediate efficacy of modern energy sealing devices in an ex vivo PA sealing model.
\end{abstract}

\begin{abstract}
Methods: Patients undergoing anatomical lung resection or lung transplantation were recruited for a prospective cohort pilot study. Four devices were evaluated: Harmonic Ace (Ethicon, Cincinnati, Ohio), Thunderbeat (Olympus, Tokyo, Japan), LigaSure (Covidien, Boulder, Colo), and Enseal (Ethicon; Cincinnati, Ohio). After anatomical lung resection, the PA branches were dissected in vitro. Sealing was then performed with 1 of the sealing devices, the vessel was slowly pressurized, and the bursting pressure was recorded.
\end{abstract}

Results: Forty-nine PA branches were sealed in 14 patients. The mean PA branch diameter was $7.4 \mathrm{~mm}(1.8-14.5 \mathrm{~mm})$. Ten patients had normal PA pressure and 3 had PA hypertension. The mean bursting pressure in each was as follows: Harmonic Ace group, $415.5 \mathrm{~mm} \mathrm{Hg}$ (137.1-1388.4 mm Hg), Thunderbeat group, $875 \mathrm{~mm} \mathrm{Hg}$ (237.1-2871.3 mm Hg); LigaSure group, $214.7 \mathrm{~mm} \mathrm{Hg}(0-579.6 \mathrm{~mm} \mathrm{Hg})$; Enseal group, $133.7 \mathrm{~mm} \mathrm{Hg}(0-315.38 \mathrm{~mm} \mathrm{Hg})$. There were 2 complete sealing failures: LigaSure (diameter $6.78 \mathrm{~mm}$ ) and Enseal (diameter $8.3 \mathrm{~mm}$ ).

Conclusions: In this pilot study to examine energy sealing of PA branches in a simulated ex vivo model, vascular sealing using energy was effective and was able to sustain high intraluminal bursting pressures. Further research is needed to determine the in vivo and long-term safety of PA branch energy sealing. (J Thorac Cardiovasc Surg 2014;148:3219-23)

Video-assisted thoracic surgery (VATS) lobectomy is currently the preferred treatment modality for stage I non-small cell lung cancer in many centers. Although it is a safe and effective technique in experienced hands, only a minority of anatomical pulmonary resections are currently being performed by VATS. In an analysis using the Nationwide Inpatient Sample database in the United States, only $15 \%$ of anatomical lung resections were performed by VATS. ${ }^{1}$

Although effective and safe in experienced hands, VATS lobectomy is not devoid of risk. Intraoperative surgical

From the CETOC - CHUM Endoscopic Tracheobronchial and Oesophageal Center, Division of Thoracic Surgery, Department of Surgery, University of Montréal, Montréal, Québec, Canada.

Funding for this study was provided by the Marcel and Rolande Gosselin Chair in Thoracic Surgical Oncology and the Thoracic Surgery Research Foundation of Montreal. The role of the studies sponsors were in funding of research personnel, equipment, software and hardware for the study.

Disclosures: Moishe Liberman reports grant support from Ethicon Endosurgery. All other authors have nothing to disclose with regard to commercial support.

Presented in part at the 50th Annual Meeting of the Society of Thoracic Surgeons. Orlando, Florida, January 2014.

Received for publication March 31, 2014; revisions received May 14, 2014; accepted for publication May 23, 2014; available ahead of print Aug 12, 2014

Address for reprints: Moishe Liberman, MD, PhD, CETOC, Division of Thoracic Surgery, Centre Hospitalier de l'Université de Montréal, 1560 rue Sherbrooke

Est, 8e CD - Pavillon Lachapelle, bureau D-8051, Montréal, Québec, Canada

H2L 4M1 (E-mail: moishe.liberman@umontreal.ca).

$0022-5223 / \$ 36.00$

Copyright $\odot 2014$ by The American Association for Thoracic Surgery

http://dx.doi.org/10.1016/j.jtcvs.2014.05.089 complications can be catastrophic at times. Complications include pulmonary vascular injuries (pulmonary artery [PA], pulmonary vein) necessitating urgent conversion to open thoracotomy and even death. ${ }^{2}$ Published conversion rates range from $2 \%$ to $20 \%$. $^{3-6}$ The technical difficulty and danger of VATS lobectomy are primarily related to PA branch dissection and manipulation and this is the main issue for many thoracic surgeons regarding the adoption of VATS lobectomy as the primary treatment modality for stage I lung cancer.

Vascular ligation and sealing using energy devices may allow the surgeon to safely seal PA branches with minimal dissection, manipulation, and possibly lower vascular injury rates. Energy sealing might be superior to stapling devices because it eliminates the need for excessive tissue dissection around the pulmonary vessels, which in turn may decrease the incidence of vascular injuries during VATS lobectomy.

The primary objective of the current study was to evaluate and compare the immediate efficacy of modern energy sealing devices in PA branch sealing and division using an ex vivo PA sealing model.

\section{MATERIALS AND METHODS}

The study consists of a prospective, preclinical, feasibility pilot study (ClinicalTrials.gov Identifier: NCT01871597) to evaluate modern energy sealing devices for sealing PA branches of various sizes.

Patients with nonhilar tumors undergoing anatomical pulmonary lung resection either by VATS or thoracotomy were enrolled prospectively. 


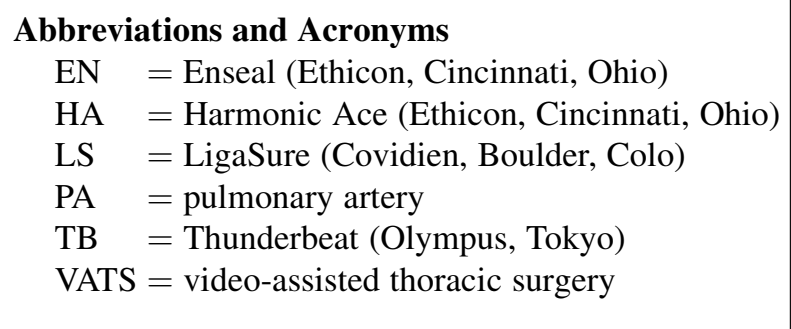

The study also included explanted lungs from lung transplant recipients. Patients with hilar lung tumors with proximity to major PAs, which may have affected the integrity of the pathologic vascular margin, were excluded.

The study was approved by the institutional review board at the Centre de Recherche, Centre Hospitalier de l'Université de Montréal, Montreal, Quebec, Canada.

Eligible patients included (1) patients with nonhilar tumors undergoing anatomical pulmonary lung resection by either VATS or open thoracotomy, (2) patients undergoing lung explant before lung transplantation, and (3) patients undergoing multiple visceral organ retrieval in which the lungs were not suitable for transplant. All patients were prospectively enrolled and gave consent before pulmonary explantation. Exclusion criteria included inability to consent (patient or family member in case of recipient organ), patient less than 18 years old, and patients with hilar tumors in proximity to major PAs that might affect the integrity of the pathologic vascular margin.

Intraoperative techniques did not differ from standard resection techniques and blood vessel ligation was performed according to standard operative procedures using either endostaplers or direct ligation of the pulmonary vessels.

After resection and removal of the resected specimen, the specimen was examined ex vivo, in a nonsterile field in the operative room. The lobar PA and its main segmental branches were sharply dissected. Cannulation of a major segmental PA branch was performed using a pressurization and monitoring device specifically designed for this study (Figure 1). The cannula was secured with a 2-0 silk suture.

The equipment for vascular pressurization and pressure monitoring/ recording was designed, developed and tested specifically for this project. A prototype vascular pressurization device with real-time, ultraprecision, intralumenal vascular pressure monitoring (up to 10 recordings per second) and software was developed by our research team in conjunction with Neptronic (Saint Laurent, Quebec, Canada). This device allows for controlled vascular pressurization with precise monitoring of pressure inflection and burst pressures. All pressure measurements were recorded and the time from initial vascular pressurization to PA bursting pressure was presented graphically.

All distal segmental branches of the PA were ligated to maintain the pressure throughout the catheterized segmental branch. An initial pressure of $25 \mathrm{~mm} \mathrm{Hg}$ was obtained by inflating the PA vessel with normal saline. The lobar PA and the main segmental branch diameters were measured using a digital caliper (Mastercraft Digital Caliper \#58-6800-4; Canadian Tire, Toronto, Ontario, Canada) from vascular adventitia to adventitia. The lobar PA and the main segmental arteries were sealed using 1 of the following devices: Harmonic Ace (HA) (Ethicon, Cincinnati, Ohio), Thunderbeat (TB) (Olympus, Tokyo, Japan), LigaSure (LS) (Covidien, Boulder, Colo), and Enseal (EN) (Ethicon, Cincinnati, Ohio). The sealing was performed with an intravascular pressure of $25 \mathrm{~mm} \mathrm{Hg}$ in order to simulate normal human PA pressures. A new vascular sealing device was used for each patient. Each specimen's PA branches were sealed with the same device.

After division of the PA, normal saline solution was injected through the controlled pressure syringe pump in order to achieve an intralumenal vascular pressure until the bursting pressure was reached. Intraluminal pressure was recorded every 0.125 seconds. This permitted the exact recording of all pressure changes and ascertainment of the precise bursting pressure, which was manifested by a sudden drop in intraluminal pressure despite maintained saline inflation.

The preoperative PA pressure was ascertained by reviewing the echocardiography results performed during the preceding year. Asymptomatic patients and patients without underlying pulmonary conditions that might predispose to pulmonary hypertension were considered to have a normal PA pressure in the absence of a formal echocardiogram.

Analysis consisted of between-group comparisons of the efficacies and bursting pressure of each sealing method studied. The primary outcome for analysis was the gross intergroup comparisons of mean PA burst pressures. Statistical testing comparing between-group differences was not performed because of the small sample size and heterogeneity between groups in this preliminary pilot study.

\section{RESULTS}

Energy sealing of PA branches was performed on 14 anatomical lung resections in 14 patients; 7 women and 7 men, aged from 27 to 79 years (mean, 60 years). Eleven patients were operated on for lung cancer and 3 specimens were explanted recipient lungs from transplant recipients (2 with idiopathic pulmonary fibrosis, 1 with cystic fibrosis). No patient had systemic vascular disease. Five patients had systemic hypertension. Five patients had diabetes. Four patients had varying degrees of renal disease.

Eleven patients had normal PA pressures. One patient had severe pulmonary hypertension with a mean PA pressure of $52 \mathrm{~mm} \mathrm{Hg}$. Two patients had mild to moderate pulmonary hypertension (mean, $46 \mathrm{~mm} \mathrm{Hg}$ and $37 \mathrm{~mm} \mathrm{Hg}$ ).

In the patients undergoing lobectomy, there were 3 right upper lobes, 4 right lower lobes, and 4 left upper lobes. The mean number of energy-sealed arteries in lobectomy cases was 1.55 (range, 1-3). In cases of recipient lungs from lung transplantation, the PAs of both lungs were dissected and energy sealing was performed. The mean number of energy-sealed arteries in lung transplant recipient lungs was 10.67 (range, 4-17).

Energy sealing was performed in 49 lobar and segmental PA branches. The diameter of sealed arteries ranged from $1.81 \mathrm{~mm}$ to $14.52 \mathrm{~mm}$ (mean, $7.47 \mathrm{~mm}$; standard deviation [SD], $2.71 \mathrm{~mm}$ ) (Figure 2).

HA was used in 5 patients and a total of 15 arteries were sealed. Two patients had documented pulmonary hypertension in this group (mean PA pressures, $52 \mathrm{~mm} \mathrm{Hg}$ and 37 $\mathrm{mm} \mathrm{Hg}$ ). PA branch diameter ranged from $3.55 \mathrm{~mm}$ to $12.71 \mathrm{~mm}$ (mean, $6.56 \mathrm{~mm}$ ). Bursting pressure in PA branches ranged from $137.1 \mathrm{~mm} \mathrm{Hg}$ to $1388.4 \mathrm{~mm} \mathrm{Hg}$ (mean, $415.5 \mathrm{~mm} \mathrm{Hg}$; SD, 361.18). There were no sealing failures in any PA branch sealed with the HA.

LS was used in 4 patients and a total of 12 arteries were sealed. All patients in the LS group had normal PA pressures. PA branches ranged from $1.81 \mathrm{~mm}$ to $14.52 \mathrm{~mm}$ (mean, $7.44 \mathrm{~mm}$ ). There was 1 complete sealing failure in 1 patient manifested by leakage of saline immediately after sealing and the inability of the vessel to 
TABLE 1. Energy devices used in the study

\begin{tabular}{lllll}
\hline \multicolumn{1}{c}{ Energy sealing device } & \multicolumn{1}{c}{ Hand piece } & $\begin{array}{c}\text { Length and } \\
\text { diameter }\end{array}$ & \multicolumn{1}{c}{$\begin{array}{c}\text { Lateral thermal } \\
\text { spread (mm) }\end{array}$} \\
\hline Harmonic Scalpel (Ethicon, Cincinnati, Ohio) & Harmonic Ace & $36 \mathrm{~cm}, 5 \mathrm{~mm}$ & Ultrasound adaptive tissue technology & $0-3$ \\
LigaSure (Covidien, Boulder, Colo) & Dolphin Tip & $37 \mathrm{~cm}, 5 \mathrm{~mm}$ & Advanced bipolar & 4.4 \\
Enseal (Ethicon, Cincinnati, Ohio) & Enseal Trio & $35 \mathrm{~cm}, 5 \mathrm{~mm}$ & Advanced bipolar & 1.1 \\
Thunderbeat (Olympus, Tokyo, Japan) & TB-0545FC, Front Grip & $45 \mathrm{~cm}, 5 \mathrm{~mm}$ & Ultrasonic and advanced bipolar & Unknown \\
\hline
\end{tabular}

hold pressurized saline (diameter, $6.78 \mathrm{~mm}$ ). Another vessel had a bursting pressure of $60 \mathrm{~mm} \mathrm{Hg}$ (diameter, $7.47 \mathrm{~mm}$ ). Bursting pressures ranged from $0 \mathrm{~mm} \mathrm{Hg}$ to $579.6 \mathrm{~mm} \mathrm{Hg}$ (mean, $214.74 \mathrm{~mm} \mathrm{Hg}$; SD, $170.21 \mathrm{~mm} \mathrm{Hg}$ ). In the LS group, smaller PA branches tended to have higher bursting pressures than larger ones.

TB was used in 3 patients and a total of 13 arteries were sealed. One patient in this group had pulmonary hypertension (mean PA pressure, $46 \mathrm{~mm} \mathrm{Hg}$ ). PA branch diameters in this group ranged from $4.46 \mathrm{~mm}$ to $10.15 \mathrm{~mm}$ (mean, $8.01 \mathrm{~mm}$ ). There were no sealing failures in any PA branch sealed with the TB. Bursting pressures ranged from $237.08 \mathrm{~mm} \mathrm{Hg}$ to $2871.31 \mathrm{~mm} \mathrm{Hg}$ (mean, $847.96 \mathrm{~mm} \mathrm{Hg}$; SD, $682.52 \mathrm{~mm} \mathrm{Hg}$ ).

EN was used in 3 patients and a total of 9 arteries were sealed. All patients had normal PA pressures preoperatively. PA branch diameters ranged from $4.98 \mathrm{~mm}$ to $12.89 \mathrm{~mm}$ (mean, $8.25 \mathrm{~mm}$ ). There was $1 \mathrm{com}-$ plete failure in PA sealing using EN (diameter, $8.31 \mathrm{~mm}$ ). Three PA branches had bursting pressure less than $100 \mathrm{~mm} \mathrm{Hg} \mathrm{(53.13} \mathrm{mm} \mathrm{Hg,} 63.65 \mathrm{~mm} \mathrm{Hg}$, and $74.67 \mathrm{~mm} \mathrm{Hg}$ ). Bursting pressures in the EN group ranged from 0 to $315.38 \mathrm{~mm} \mathrm{Hg}$ (mean, $133.67 \mathrm{~mm} \mathrm{Hg}$; SD, $105.89 \mathrm{~mm} \mathrm{Hg})$.

\section{DISCUSSION}

PA ligation and sealing is a critical step in anatomical lung resection. During VATS lobectomy, PA sealing is typically performed using endostaplers or clips. ${ }^{7,8}$ Endostaplers are effective for ligating pulmonary vessels with burst pressures in porcine PAs reaching up to $297 \mathrm{~mm} \mathrm{Hg}^{9}$ However, endostaplers are bulky, rigid, and have a large footprint making application and stapling of pulmonary vessels awkward, difficult, and sometimes dangerous.

Intraoperative surgical complications occurring during VATS lobectomy can be sometimes be catastrophic. Complications include pulmonary vascular injuries (PA, pulmonary vein) necessitating urgent conversion to open thoracotomy and even death. ${ }^{2}$ Published conversion rates range from $2 \%$ to $20 \% .^{3-6}$ In a Canadian study published in 2011 on the causes of VATS conversion to thoracotomy for 237 procedures, the conversion rate from VATS to open thoracotomy was $13.5 \% .^{2} \mathrm{PA}$ injury alone constituted $37.5 \%$ of all conversions. Flores and colleagues ${ }^{10}$ demonstrated catastrophic complications in 13 cases in their series of 633 cases. Five patients had PA injury or transection. Proper dissection of all tissue around PA branches is sometime difficult, especially in the presence of adhesions or large, calcified, lymph nodes and may increase the risk of vascular injury.

Although it is a safe and effective technique in experienced hands, only a minority of anatomical pulmonary resections are currently being performed by VATS. In an analysis using the Nationwide Inpatient Sample database in the United States, only $15 \%$ of anatomical lung resections were performed by VATS. ${ }^{1}$ However, according to the procedures recorded in the Society of Thoracic Surgeons database (voluntary contribution), the number of VATS anatomical lung resections performed in North America is increasing (8\% in 2003 vs $44.7 \%$ in 2010). ${ }^{11}$ In Europe, less than $10 \%$ of all major anatomical lung resections are performed by VATS. ${ }^{10}$

The technical difficulty and danger of VATS lobectomy is in part related to PA branch manipulation, dissection,

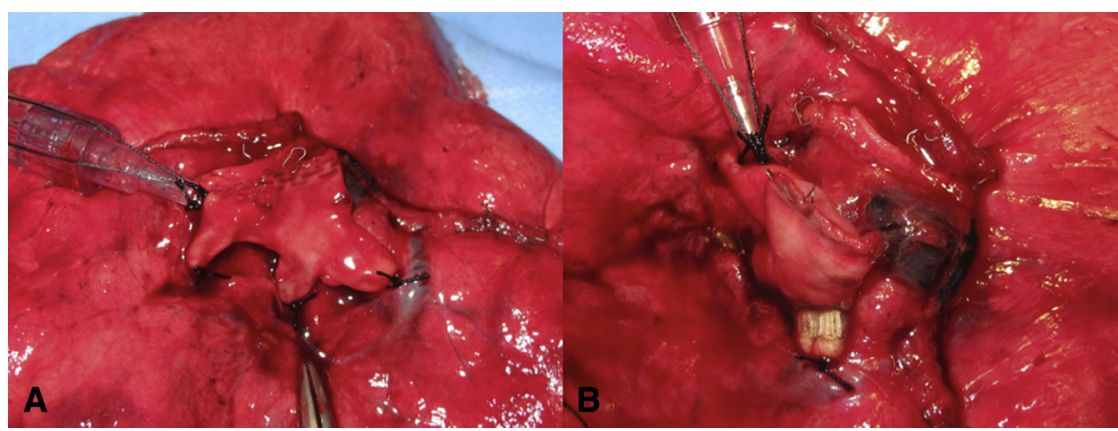

FIGURE 1. Dissected and ligated segmental and subsegmental pulmonary artery branches. Pressurization and pressure recording is achieved through cannulation of 1 arterial branch (A). Pulmonary artery after LigaSure sealing (B). 


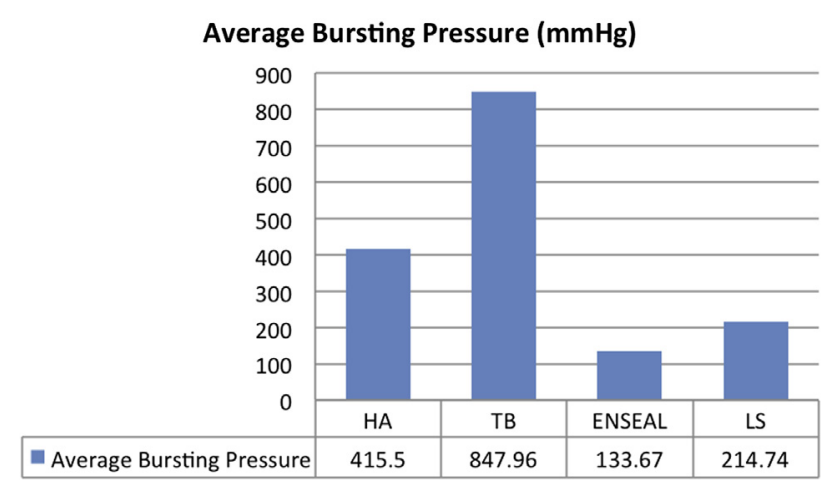

FIGURE 2. Average bursting pressures of energy sealing devices. $H A$, Harmonic Ace; $L S$, LigaSure; $T B$, Thunderbeat.

stapling, and division. PA manipulation is the main issue for many thoracic surgeons regarding the adoption of VATS lobectomy. An effective and safe way to decrease the manipulation and wide dissection required on the PA branches is required to make these procedures a little safer and therefore more prevalent.

Others have evaluated energy sealing of PA vessels. Albanese and colleagues ${ }^{12}$ performed pediatric VATS lobectomy using LS. They reported 14 VATS lobectomies in children aged 3 to 15 months. LS was used to transect the main pulmonary vessels and complete the fissure if needed. There were no intraoperative or postoperative complications. ${ }^{12}$ Another series of 6 energy VATS lobectomies in children (10 months old) was published in 2006. LS was used to seal the pulmonary lobar vessels. There were no intraoperative complications. Two patients had postoperative hemothorax, which resolved spontaneously. ${ }^{13}$

Energy devices have been evaluated and used in the abdomen to seal systemic vessels and have been proved to be effective. ${ }^{14,15}$ Although thermal spread is always a concern in energy sealing, modern energy sealing devices produce much less lateral thermal spread than conventional bipolar devices (Table 1). ${ }^{16-21}$

The ability of the sealed arteries to resist intraluminal pressure is the most important factor determining the safety of energy sealing. Santini and colleagues ${ }^{22}$ decided that a bursting pressure of sealed PA branches greater than 150 $\mathrm{mm} \mathrm{Hg}$ is acceptable and safe. Although this value was used in subsequent studies, ${ }^{23}$ this critical bursting pressure has not been validated. We have observed that patients with higher PA pressures had higher PA burst pressures after vascular energy sealing. This is likely a result of the increased thickness of the elastic fiber layer in the arterial wall caused by long-standing increased intraluminal pressures.

Most of the patients enrolled in the current study had normal PAs. Patients with higher PA pressure were not excluded. If patients with abnormal PAs are excluded, the average burst pressure was lower in all groups (HA, $326.08 \mathrm{~mm} \mathrm{Hg}$; LS, $214.74 \mathrm{~mm} \mathrm{Hg}$; EN, $83.31 \mathrm{~mm}$ $\mathrm{Hg}$; and $\mathrm{TB}, 573.55 \mathrm{~mm} \mathrm{Hg}$ ). PA hypertension seems to be a protective factor in PA vascular sealing. However, even normal pulmonary vessels sealed with acceptably high burst pressures.

There was a significant difference in efficacy and burst pressures based on the energy platform used. Devices using ultrasound-sealing technology (HA) seemed superior to advanced bipolar technology (LS and EN) in sealing PAs. Moreover, 2 complete sealing failures were observed in the LS and EN groups. Combining the 2 technologies (TB) resulted in increased mean bursting pressures.

Tanaka and colleagues ${ }^{24}$ used the HA scalpel to seal 43 PAs and 13 pulmonary veins in an animal model. The bursting pressure of the arteries sealed was more than 100 $\mathrm{mm} \mathrm{Hg}$ in all arteries except 1 . Tsunezuka and colleagues ${ }^{25}$ evaluated the bursting pressure of PAs sealed with the LS device in a human model during VATS lung resections. LS was used to seal segmental and subsegmental PAs less than $5 \mathrm{~mm}$ in diameter. High bursting pressures were observed. There were higher bursting pressures in PAs smaller than $5 \mathrm{~mm}$ compared with PAs larger than $5 \mathrm{~mm}$. Lesser and colleagues ${ }^{26}$ compared bursting pressures in PAs sealed with LS with suture-ligated arteries. The mean bursting pressure in small PAs (3-5 mm) was $315 \mathrm{~mm} \mathrm{Hg}$ and $156 \mathrm{~mm} \mathrm{Hg}$ in larger PAs $(6-8 \mathrm{~mm})$. To date, there have been no studies evaluating the use of EN and TB in PA sealing.

The results of the present study were similar to others except for the PA branches sealed with the HA. Larger PAs sealed with HA burst at higher bursting pressures. Tanaka and colleagues $^{18}$ observed that histologic examination of the PAs sealed with HA in a swine model showed degeneration of the collagen and elastic fibers and tight sealing at the resected stump of the PA. Lesser and colleagues $^{26}$ observed that histologic examination of the PAs sealed with LS revealed only adventitial fusion with retraction and invagination of the intima and media layers without fusion. This histologic difference in the mechanism of PA sealing may explain the lower bursting pressures with larger arteries sealed by either ultrasound or advanced bipolar technology.

\section{Limitations}

The present study is a preclinical study providing pilot data using 4 commonly used advanced energy sealing devices. The sample size is small (14 patients and 49 PAs). Larger samples with different PA pressures and vessel sizes will be needed to confirm the pilot data gained from this study. Histologic examinations will be needed in future studies to compare and evaluate the different sealing mechanisms of the advanced energy sealing devices. Saline was used instead of blood to pressurize the vessels in this 
study. During vascular sealing, when the vessel is sealed, it is completely occluded with pressure from the jaws of the device and therefore there is no blood within the lumen. Using blood in the pressurization system would have required drawing blood from the patient, which would have caused undue risk to the participants, and therefore saline was used instead.

\section{CONCLUSIONS}

In this pilot study evaluating 4 commercially available energy devices, energy sealing of PA branches was effective and shown to sustain high intraluminal bursting pressures in a simulated ex vivo environment. In this pilot study with a small number of patients, ultrasound technology seemed to be superior to advanced bipolar technology, but for that conclusion to be verified, a larger group of patients must be evaluated. Further research is needed to determine the long-term safety of PA energy sealing in an in vivo environment.

Vascular pressurization and measurement devices were designed and produced specifically for this study by Neptronic, Saint Laurent, Quebec, Canada.

\section{References}

1. Paul S, Sedrakyan A, Chiu YL, Nasar A, Port JL, Lee PC, et al. Outcomes after lobectomy using thoracoscopy vs thoracotomy: a comparative effectiveness analysis utilizing the Nationwide Inpatient Sample database. Eur J Cardiothorac Surg. 2013:43:813-7.

2. Gazala S, Hunt I, Valji A, Stewart K, Bedard E. A method of assessing reasons for conversion during video-assisted thoracoscopic lobectomy. Interact Cardiovasc Thorac Surg. 2011;12:962-4.

3. McKenna RJ, Houck W, Fuller CB. Video-assisted thoracic surgery lobectomy: experience with 1100 cases. Ann Thorac Surg. 2006;6:421-6.

4. Walker WS, Codispoti M, Soon S-Y, Stamenkovic S, Carnochan F, Pugh G. Long-term outcomes following VATS lobectomy for non-small cell bronchogenic carcinoma. Eur J Cardiothorac Surg. 2003;23:397-402.

5. Gharagozloo F, Tempesta B, Margolis M, Alexander EP. Video-assisted thoracic surgery lobectomy for stage I lung cancer. Ann Thorac Surg. 2003;7:1009-15.

6. Nomori H, Horio H, Naruke T, Suemasu K. What is the advantage of a thorascopic lobectomy over a limited thoracotomy procedure for lung cancer surgery? Ann Thorac Surg. 2001;6:879-84.

7. Seong W, Kang H, Kim T, Moon J, Park K, Kim T. Video-assisted thoracoscopic lobectomy in children: safety, efficacy, and risk factors for conversion to thoracotomy. Ann Thorac Surg. 2013;95:1236-42.

8. Solaini L, Prusciano F, Bagioni P, Di Francesco F, Poddie B. Video-assisted thoracic surgery (VATS) of the lung: analysis of intraoperative and postoperative complications over 15 years and review of the literature. Surg Endosc. 2008;22: 298-310.
9. Kirschbaum A, Sasse T, Palade E. Burst pressures of the central pulmonary artery after bipolar vessel sealing - examination in an ex vivo model. Zentralbl Chir. 2014;139:342-5 [in German].

10. Flores RM, Thekweazu U, Dycoco J, Rizk NP, Rusch VW, Bains MS, et al Video-assisted thoracoscopic surgery (VATS) lobectomy: catastrophic intraoperative complications. J Thorac Cardiovasc Surg. 2011;142:1412-7.

11. Ceppa D, Kosinski A, Berry M, Tong B, Harpole D, Mitchell J, et al. Thoracoscopic lobectomy has increasing benefit in patients with poor pulmonary function: a Society of Thoracic Surgeons Database analysis. Ann Surg. 2012;256: 487-93.

12. Albanese CT, Sydorak RM, Tsao K, Lee H. Thoracoscopic lobectomy for prenatally diagnosed lung lesions. J Pediatr Surg. 2003;38:553-5.

13. Cano I, Antón-Pacheco JL, García A, Rothenberg S. Video-assisted thoracoscopic lobectomy in infants. Eur J Cardiothorac Surg. 2006;29:997-1000.

14. Rimonda R, Arezzo A, Garrone C, Allaix ME, Giraudo G, Morino M Electrothermal bipolar vessel sealing system vs. harmonic scalpel in colorectal laparoscopic surgery: a prospective, randomized study. Dis Colon Rectum 2009;52:657-61.

15. Bessa S, Abdel-Razek H, Sharaan A, Bassiouni AE, El-Khishen A, El-Kayal A Laparoscopic cholecystectomy in cirrhotics: a prospective randomized study comparing the conventional diathermy and the harmonic scalpel for gallbladder dissection. J Laparoendosc Adv Surg Tech A. 2011;21:1-5.

16. Matthews BD, Pratt BL, Backus CL, Kercher KW, Mostafa G, Lentzner A, et al Effectiveness of the ultrasonic coagulating shears, LigaSure vessel sealer, and surgical clip application in biliary surgery: a comparative analysis. Am Surg. 2001;67:901-6.

17. Goldstein SL, Harold KL, Lentzner A, Matthews BD, Kercher KW, Sing RF, et al. Comparison of thermal spread after ureteral ligation with the LaparoSonic ultrasonic shears and the Ligasure system. J Laparoendosc Adv Surg Tech A. 2002;12:61-3.

18. Phillips CK, Hruby GW, Durak E, Lehman DS, Humphrey PA, Mansukhani MM, et al. Tissue response to surgical energy devices. Urology. 2008;71:744-8.

19. Campbell PA, Cresswell AB, Frank TG, Cuschieri A. Real-time thermography during energized vessel sealing and dissection. Surg Endosc. 2003;17:1640-5.

20. Landman J, Kerbl K, Rehman J, Humphrey PA, Collyer W, Olweny E, et al. Evaluation of a vessel sealing system, bipolar electrosurgery, harmonic scalpel, titanium clips, endoscopic gastrointestinal anastomosis vascular staples and sutures for arterial and venous ligation in a porcine model. J Urol. 2003;169: 697-700.

21. Abstracts of the Global Congress of Minimally Invasive Gynecology, 34th Annual Meeting of the American Association of Gynecologic Laparoscopists, Chicago, Ill, November 9-12, 2005. J Minim Invasive Gynecol. 2005;12(5 Suppl):S1-124.

22. Santini M, Vicidomini G, Fiorello A, Laperuta P, Busiello L. Electrotherma bipolar tissue sealing systems in lung surgery. Multimed Man Cardiothorac Surg. 2008. doi:10.1510/mmcts.2007.003111.

23. Lacin T, Batirel HF, Ozer K, Demirutku A, Ahiskali R, Yuksel M. Safety of a thermal vessel sealer on main pulmonary vessels. Eur J Cardiothorac Surg. 2007:31:482-5.

24. Tanaka T, Ueda K, Hayashi M, Hamano K. Clinical application of an ultrasonic scalpel to divide pulmonary vessels based on laboratory evidence. Interact Cardiovasc Thorac Surg. 2009;8:615-8.

25. Tsunezuka Y, Waseda R, Yachi T. Electrothermal bipolar vessel sealing device LigaSureV ${ }^{\mathrm{TM}}$ for pulmonary artery ligation - burst pressure and clinical experiences in complete video-assisted thoracoscopic major lung resection for lung cancer. Interact Cardiovasc Thorac Surg. 2010;11:229-33.

26. Lesser T, Wolfram F, Boltze C. Sealing of pulmonary arteries with LigaSure: in vivo and ex vivo examinations. J Thorac Cardiovasc Surg. 2013;145:1525-8. 